\title{
A fronteira dos desencontros
} MARTINS, José de Souza. Fronteira: a degradação do outro nos confins do humano. São Paulo: Hucitec, 1997. 213 páginas.

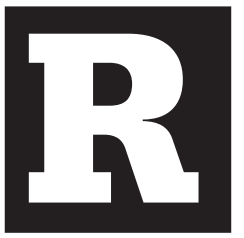

esultantes de pesquisas desenvolvidas nos últimos trinta anos, metade dos quais em diferentes ocasióes e em diferentes pontos da região amazônica (p. 13) na execução do Projeto Tensões sociais nas frentes de expansão da Amazônia Legal, cujo horizonte empírico ocupa os Estados de Mato Grosso, Rondônia, Acre, Amazonas, Pará, Maranhão e Tocantins, os quatro capítulos que compõem o livro têm como eixo fundamental da análise, numa dimensão, propriamente sociológica e antropológica (p. 13), os aspectos essenciais da multiplicidade da fronteira. O elemento unificador dos estudos é o desencontro entre diferentes grupos sociais que juntam (e separam) pedaços de vida entre a esperança e o destino trágico. É assim, que posseiros, garimpeiros, indígenas, missionários, colonos e capitalistas pautam seus destinos pela exploração ou pela solidariedade, pela idéias de futuro ou pela certeza de uma derrota histórica, pela escravidão por dívida que faz com que o assujeitado não chegue à condição de sujeito, pela falta de terra em meio à imensidão da terra (e da floresta) compondo as máscaras que se esfacelam na tragédia da fronteira, onde José de Souza Martins vai esquadrinhar a face sem retoques de um espaço social marcado pelos

\footnotetext{
* Sociólogo, Doutor em Sociologia pelo PPGS/UFRGS e Professor do Centro de Ciências Humanas da UNISINOS.
} 
caminhos e pelos descaminhos.

Baseando-se em técnicas artesanais de investigação e em técnicas de inserção pedagógica temporária nos grupos e comunidades estudados (p. 15), realiza pertinentes críticas àqueles estudos que, ao privilegiarem a ideologia do pioneiro, deixam de lado o essencial, o aspecto trágico da fronteira (p. 15). Isso porque o discurso dominante, constituído, segundo Martins, pelo imaginário do poder, no que se refere às fronteiras dos Estados Nacionais no senso comum e, em grande medida no discurso acadêmico, aborda a formação das fronteiras internas destacando figuras proeminentes ou grupos sociais que, desbravando um território selvagem, despovoado, teriam construído a civilização no espaço conquistado. Esse imaginário que destaca a figura do pioneiro, embasa-se em grande medida nos estudos de Frederick Jackson Turner ( The Frontier in American History, New York: Henry Holt and Company, 1921.) que, ao investigar a marcha para o Oeste na ocupação e demarcação da fronteira interna norte-americana, omite, conforme demonstra Martins, a luta pela terra em decorrência da invasão de territórios indígenas, a violência ocasionada pela conquista e os desencontros entre nativos e " civilizados". A análise centra-se nas noções de frente pioneira e frente de expansão, desenvolvidas amplamente no quarto capítulo, cuja aproximação e confronto constituem o fio condutor dos quatro textos, demonstrando-se que este procedimento analítico é necessário para a compreensão da fronteira.

A frente pioneira (p. 186) se define economicamente pela presença do capital na produção (p. 186), e a frente de expansão, como uma concepção que percebe a ocupação do espaço sem a mediação do capital, tomando como referência primeira o indígena e significando a situação de contato. Situação essa que fora analisada por antropólogos como Roberto Cardoso de Oliveira - como indica Martins - que, em estudos dos anos sessenta haviam apontado que as relações entre os protagonistas (índios e brancos) expressavam um contato conflitual (p. 155). Ambas representam momentos históricos distintos e combinados de diferentes modalidades da expansão territorial do capital [...] expressóes de um mesmo processo (p. 159, nota 20). 
Se entendermos que a fronteira tem dois lados e não um lado só, o suposto lado da civilização; se entendermos que ela tem o lado de cá e o lado de lá, fica mais fácil e mais abrangente estudar a fronteira como concepção de fronteira do humano. Nesse sentido, diversamente do que ocorre com a frente pioneira, (na frente de expansão) sua dimensão econômica é secundária (p. 163).

Ao estudar a frente de expansão brasileira, Martins busca no desvendamento dos segredos mais profundos da situação de fronteira ( $\mathrm{p}$. 16), reconstruídos analiticamente mediante a inserção social, os nexos da conflitualidade na fronteira, lugar que, na ausência expressa e direta das instituições do Estado (p. 40), pauta grande parte das relações pela dominação personalizada, mediante a ação de forças repressivas do privado (p. 40).

A captura do outro; o rapto de mulheres e crianças nas fronteiras étnicas do Brasil, constitui o primeiro capítulo do livro e analisa, a partir de extensa documentação histórica e socioantropológica, um dos indicadores dos desencontros das frentes de expansão que é o do rapto de pessoas, principalmente de mulheres e crianças pelos grupos tribais entre si, pelos indígenas em relação aos regionais, ou seja, aos brancos e pelos brancos na captura dos índios. O rapto é expressão do desencontro entre o eu e o outro, representando fronteira étnica e destino como demonstração de que o eu (o raptor) e o outro (o raptado) desconhecem - como indica Martins o recíproco reconhecimento da humanidade do eu e do outro (p. 73), como face visível da concepção de pessoa na situação de fronteira e da própria concepção de fronteira de diferentes populaçôes indigenas (p. 73) e, poderíamos acrescentar, também de "civilizadas". Quando na recusa do outro, efetiva-se a recusa trágica da alteridade. 
Embora Martins declare que o estudo sobre o rapto - e este não pode ser visto somente como delito, mas antes como elemento de mediação numa forma particular de definição da situação social da fronteira - tem por finalidade enriquecer a compreensão da problemática enquanto fronteira étnica, sem dúvidas o estudo apresenta importantes contribuições para as análises da atuação do Estado e, portanto elementos fundamentais para estudos das fronteiras jurídico-políticas e das relações (ou ausência de relações sólidas) entre as esferas públicas e privadas nas fronteiras internas da sociedade brasileira.

No segundo capítulo intitulado $A$ reprodução do capital na frente pioneira e o renascimento da escravidão, o olhar sociológico de Martins detém-se sobre a frente pioneira - que é, como afirma o autor, um dos momentos de um mesmo processo ou seja, a frente pioneira como momento do processo do capital (p. 94). A análise centra-se na escravidão por dívida ou peonagem, expressões do cativeiro no Capitalismo da fronteira do Brasil, demonstrando-se que essa forma de exploração constitui um dos elementos da acumulação primitiva no interior da reprodução ampliada do capital, a presença contemporânea de relações sociais do passado reatualizadas enquanto produtos do capital. Os números apresentados pelo autor são impressionantes: No período de 1970 a 1993 houve denúncias de ocorrência de trabalho escravo em 431 fazendas; destas, 308 na Amazônia e as demais, em outras regiões do país. Especificamente nas fazendas, foi estimado que, somadas as denúncias de diferentes épocas, houve pouco mais de 85 mil trabalhadores escravizados (p. 89), número esse, segundo o próprio autor, que é muito inferior ao real, visto que se baseia somente nos casos daquelas fazendas denunciadas. Tais dados, aliados aos inúmeros casos de torturas de peões e assassinatos em tentativas de fugas, são significativos na demonstração da escravidão de hoje como componente do próprio processo do capital(p. 91), em que este último tira vantagens comparativas do atraso social e econômico (p. 112).

O terceiro capítulo denominado Regimar e seus amigos: a criança na 
luta pela terra e pela vida inicia com importante análise crítica à sociologia convencional que, ao trabalhar com informantes privilegiados, condena um grande contingente social ao silêncio: as mulheres, as crianças, os velhos, os agregados da casa, os dependentes, os que vivem de favor. Ou os mudos da História, os que não deixam textos escritos (p. 118). Rompendo essa perspectiva, Martins coleta duas centenas de depoimentos de crianças e adolescentes em um núcleo de colonização particular (Colonia de Canarana no Mato Grosso) e em dois povoados (São Pedro da Água Branca e Floresta, no Maranhão). No primeiro caso, tem-se colonos proprietários; no segundo caso - o dos povoados - os pequenos agricultores vivem situação de instabilidade permanente, pois a condição de posseiros faz com que estejam sujeitos ao despejo por parte de pistoleiros a mando de fazendeiros. Martins escreve:

Neste texto falo da fala das crianças, que por meio dela me falam (e nos falam) do que é ser criança (e adulto) nas remotas regióes das frentes de ocupação do território, em distantes pontos da Amazônia (p. 120).

O tempo da fronteira; retorno à controvérsia sobre o tempo histórico da frente de expansão e da frente pioneira forma o quarto capítulo e parte conclusiva do livro, no qual Martins argumenta que, na contemporaneidade brasileira, o que há de sociologicamente mais relevante para definir a fronteira no Brasil é, justamente, a situação de conflito social(p. 150).

De acordo com o autor:

...a situação de fronteira (é) um ponto de referência privilegiado para a pesquisa sociológica porque encerra maior riqueza de possibilidades históricas do que outras situações sociais. 
Em grande parte porque mais do que o confronto entre grupos sociais com interesses conflitivos, agrega a esse conflito também o conflito entre historicidades desencontradas... (p. 182).

Isso faz com que o milenarismo camponês e as concepções messiânicas indígenas, apresentem-se como busca de construção de uma outra alteridade que o olhar de estranhamento do sociólogo busca desvendar, em meio a um tempo que passa a ser o tempo do capital e das 'modernas' formas de escravidão.

Por fim, queremos mencionar que a Introdução do livro e a parte inicial de cada texto apresentam reflexões metodológicas que constituem importantes lições para aqueles que, como nós, ocupam-se do permanente aprendizado de pesquisador: as implicações teóricas, os compromissos, as dificuldades, o perigo das posições ambíguas, o trabalho solitário, as situações de solidariedade ou de violência nas quais o pesquisador é envolvido, enfim, as perguntas que o pesquisador faz (e se faz). Queremos sugerir também que as notas de leitura aqui apresentadas tiveram a finalidade de propor aos sociólogos do amanhã (e de hoje também) um estudo mais demorado desta e de outras obras de José de Souza Martins nas quais estão presentes, de forma relacional, profundo compromisso ético e contundente denúncia daquilo que não pode ser tolerado, seja na esfera da ciência, seja na esfera das relações político-sociais.

Resenha elaborada na primeira quinzena de março de 1999. 


\section{Resumo}

A resenha propõe-se a um convite à leitura do livro destacando os elementos essenciais de cada capítulo, quais sejam, as relações entre frente pioneira e frente de expansão, o renascimento da escravidão, a fala (e o silêncio) das crianças nas frentes de ocupação e a situação de conflito social como elementos importantes no delineamento das análises contemporâneas sobre o Brasil. Apresenta, ainda, a preocupação metodológica e o compromisso político de denúncia das injustiças como traços fundamentais de José de Souza Martins.

Palavras-chave: fronteira, sociologia da conflitualidade, alteridade 